XV.-On the Atomic Weight af Titanium.

By T. E. Thокре, F.R.S., Professor of Chemistry in the Yorkshire
College, Leeds.

THE existence of the element we now call titanium was first made known in 1789 by Mr. W. Gregor: he found it in the titaniferous iron-sand in the bed of a small stream near Menaccan, in the parish of St. Keverne, in Cornwall. Hence the mineral became known as menacconite, and the metal as menachin.

In 1793, Klaproth detected the new element in a specimen of red schorl from Hungary, and, in ignorance of Gregor's discovery, he termed the metallic radicle titanium. His experiments were repeated and confirmed by Vauquelin and Hecht in 1796. Klaproth subsequently examined menacconite, and found that menachin and titanium were identical.

Although titanium is usually regarded as a comparatively rare element, its atomic weight was made the subject of investigation as far back as 1823. In that year, Heinrich Rose published a series of determinations based upon the conversion of titanium disulphide into the dioxide by heating it in a current of air, but the results were recognised by Rose himself as unsatisfactory owing to the difficulty of preparing the sulphide pure-that is, free from admixed oxide. The attempt was made to correct for the possible error by heating the sulphide in chlorine gas and weighing the residual titanic oxide, but the numbers were too discordant to permit of the deduction of any accurate value for the atomic weight. (Gillert's Annalen, 73, 155.)

In 1829, Rose (Pogg. Ann., 15, 145) made known the results of his analyses of titanium tetrachloride, a substance first obtained by Mr. E. S. George, of Leeds, by heating the cyanonitride of the blast furnaces in a stream of chlorine (Thomson, Ann. Phil., 9, 1825, 1820). The chloride was prepared by Rose by heating a mixture of the dioxide and charcoal in chlorine, and was rectified by boiling first over mercury and then over potassium. The portion selected for analysis was distilled four or five times; it was perfectly clear, and gave no indications of free chlorine on decomposition with water. Weighed portions of the chloride contained in small glass bulbs were broken under water in a stoppered bottle, the milky solution was diluted with water and mixed with a very slight excess of ammonia. The titanic acid was separated by filtration and weighed; the filtrate was gently heated to expel the free ammonia, acidulated with nitric acid, mixed 
with silver nitrate, and the silver chloride filtered off and weighed. In all, five experiments were made on quantities varying between 0.885 gram and 3.0455 grams.

Rose does not explicitly state what numbers he adopts for the atomic weights of silver and chlorine, but inasmuch as he regards $74.46^{\circ}$ of chlorine (the percentage amount of that element found by him in what he considered as the most trustworthy experiments) as equivalent to 16.82 of oxygen, $\mathrm{Cl}$ would be $35 \cdot 4$ if $\mathrm{O}$ were 16 ; and since it appeared that 1 gram of titanium tetrachloride yielded 3.0184 grams silver chloride, it follows that Ag was regarded as 108.1.*

The percentage amounts of chlorine obtained in the five experiments were respectively-

$$
74 \cdot 18 ; 74.43 ; 74: 37 ; 74: 51 ; 74: 53 \text {. }
$$

Rose, however, rejects the first result, on the ground that it was obtained from a relatively small quantity of material, and takes the mean of the others : hence the percentage composition becomes-

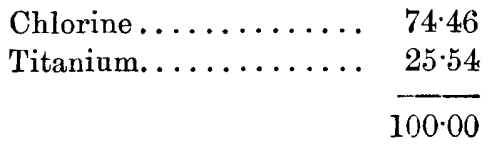

and since, according to Rose, $74: 46$ parts of chlorine are equivalent to 16.82 parts of oxygen, it follows that the percentage composition of titanium dioxide is -

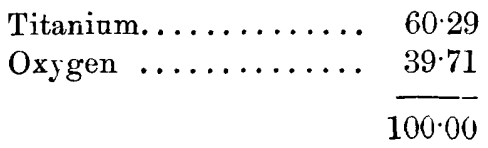

The determinations of the amount of titanic oxide directly obtained indicated that 100 parts of the tetrachloride gave respectively the following quantities of the dioxide:-

$$
42 \cdot 83 ; 42 \cdot 48 ; 42.66 ; 43 \cdot 42 ; 43.27 \text {. }
$$

Rose selects the first tbree numbers, of which the mean is 42.657 , and from these he calculates the percentage amount of oxygen in the dioxide as $4.0 \cdot 12$; if the mean of the whole be taken it becomes $41 \cdot 35$.

These results have been discussed by Becker ("Smithsonian Collections," 1880, 123); by F. W. Clarke ("Smithsonian Collections," 1882, 207); and by Meyer and Seubert ("Atomgewichte der Elemente, \&c." Breitkopf and Härtel, Leipzig, 1と83). According to Clarke, Rose's numbers afford the following values for $\mathrm{Ti}:-$

* The accepted ratios of $\mathrm{O}: \mathrm{Cl}: \mathrm{Ag}$ at that time were $100: 221 \cdot 325: 1351 \cdot 607$. 


$$
\begin{aligned}
& \text { "From percentage amount of } \mathrm{TiO}_{2} . . \quad \mathrm{Ti}=50.493 \pm 0.410 \\
& \mathrm{AgCl}: \mathrm{TiCl}_{4} \ldots \ldots \ldots \ldots, \mathrm{Ti}=48 \cdot 232 \pm 0.127 \\
& \mathrm{AgCl}: \mathrm{TiO}_{2} \ldots \ldots \ldots \ldots . \mathrm{Ti}=49.523 \pm 0.206 \\
& \mathrm{H}=1, \mathrm{O}=15 \cdot 9633, \mathrm{Cl}=35 \cdot 37, \mathrm{Ag}=107 \cdot 675,
\end{aligned}
$$

Rose himself, it should be stated, rejects the values obtained from the amount of titanic oxide, on the ground that this compound does not afford a trustworthy basis for the estimation, by reason of its hygroscopic character which prevents an accurate determination of its weight.

Meyer and Seubert, who employ the ratios-

$$
\mathrm{O}: \mathrm{Cl}: \mathrm{AgCl}=1: 6.7456: 8.96146 \text {, }
$$

calculate from the sums of the weights of $\mathrm{TiCl}_{4}, \mathrm{TiO}_{2}$, and $\mathrm{AgCl}$ in the several experiments-

$$
\begin{aligned}
& \mathrm{TiCl}_{4}: \mathrm{O}=11 \cdot 879: 1(\min .11 \cdot 866 ; \max .11 \cdot 891) \\
& \mathrm{TiO}_{2}: \mathrm{O}=5 \cdot 106: 1(\min .4 \cdot 932 ; \max .5 \cdot 152) .
\end{aligned}
$$

On the assumption that $\mathrm{H}=1$ and $\mathrm{O}=15.96$; the mean results give respectively-

$$
\begin{aligned}
& \mathrm{TiCl}_{4}: \mathrm{AgCl} \quad \mathrm{Ti}=48 \cdot 13 \text { (min. } 47 \cdot 92 ; \max .48 \cdot 32 \text { ) } \\
& \mathrm{TiO}_{2}: A g C l \quad \mathrm{Ti}=49.58(\min .46 \cdot 80 ; \max .50 \cdot 30) \text {. }
\end{aligned}
$$

There are several possible sources of error in the method employed by Rose. In the first place, repeated distillation of the tetrachloride in air leads to the formation of small quantities of Troost and Hautefeuille's oxychloride; and in the next, owing to the great care taken to avoid excess of ammonia, the precipitated oxide might well contain basic chlorides, analogous to the chlorostannic acid of Mallet, or $\mathrm{Ti}_{2} \mathrm{OCl}_{2}$, corresponding to stannous oxychloride. It will be shown further on that the precipitated oxide is very apt to retain traces of chlorine which are expelled as tetrachloride on heating, uuless it is repeatedly treated with solution of ammonia.* Moreover, prolonged and intense ignition is required to obtain the dioxide absolutely anhydrous. The final mean from Rose's numbers will also be slightly affected by the circumstance that his weighings were not reduced to a vacuum standard.

In 1830, Mosander (Pogg. Ann., 19, 212) published a series of numbers showing the percentage amount of oxygen in titanic oxide. No details are given, but the estimations are most probably based upon the decomposition of the tetrachloride by water.

* Van Bemmelen's experiments have shown with what tenacity colloidal substances like the hydrated oxides of tin and silicon, bodies analogous to titanium oxide, retain water, acids, and salts (J. pr. Chem. [2], 23, 324; 26, 227). 
In all, nine determinations appear to have been made; the results varied from 39.830 to 40.825 ; the mean of the series is 40.428 , which gives for $\mathrm{Ti} 47 \cdot 04$.

In the same year, Dumas (Ann. de Chim., 44, 288) found the vapour-density of titanium tetrachloride to be 6.836 (air $=1$ ) from which if $\mathrm{Cl}=35 \cdot 4$, Ti becomes $55 \cdot 6$. Of course this result has no other value than as serving to determine the molecular formula of the chloride. The errors incidental to the method, especially in the case of such a body as titanium tetrachloride, would certainly tend to give too high a value for the density, and hence for the atomic weight of titanium.

The determinations which have hitherto been deemed most trustworthy are those of Pierre, made in 1847 (Ann. de Chim. [3], 20, $257)$ : on these, the value for $\mathrm{Ti}$ given in the greater number of the text-books is based. Pierre, who had prepared a quantity of the tetrachloride for the purpose of studying its thermal expansion, made a number of estimations of the amount of chlorine contained in it by the method of Gay-Lussac. The chloride was obtained from the artificial oxide and was free from iron. According to Pierre, it could hardly have contained silicon chloride, as the first portions of the distillate were rejected, and its boiling point was perfectly constant. Weighed portions of the chloride, in quantities varying from 0.6325 gram to 0.8215 gram, were broken under water in well-stoppered bottles, and the chlorine in the solution was determined by the addition of a standard solution of silver. The results of the whole of the observations (nine in number) gave for Ti 49.889 . Pierre, however, was inclined to believe that only the first three results, which agreed fairly well together, were trustworthy, and he accordingly rejects the other six, which gave lower values for $\mathrm{Ti}$, on the ground that the chloride had been affected by atmospheric moisture. The first three give Ti, $50 \cdot 259(\mathrm{O}=15.963 ; \mathrm{Cl}, 35 \cdot 37$; $\mathrm{Ag}, 107 \cdot 675)$; or, adopting Meyer and Seubert's ratios, we have-

$$
\begin{aligned}
\mathrm{TiCl}_{4}: 4 \mathrm{Ag} & =2 \cdot 3730: 5 \cdot 33045 \\
& =1 \cdot 7807: 4 \\
\mathrm{TiCl}_{4}: \mathrm{O} & =12 \cdot 012: 1 \\
\mathrm{Ti}: \mathrm{O} & =3 \cdot 149: 1 \\
\mathrm{Ti}: \mathrm{H} & =50 \cdot 25: 1
\end{aligned}
$$

Pierre's results, it will be seen, differ by more than two units from those Rose obtained by weighing the silver chloride. This may be accounted for by loss of chlorine in the act of solution, by the possible presence of oxychloride, or by the coprecipitation of basic chloride, all of which circumstances would tend to decrease the amount of silver needed for complete precipitation, and hence raise 
the value of Ti. The quantities of the chloride taken for analysis (on the average about $0.8 \mathrm{gram}$ ) were scarcely sufficient for the purpose of an accurate determination of atomic weight.

The only other contribution to our knowledge of this subject is due to A. Demoly (Compt. rend., par Laurent et Gerhardt, 1849, 326; Ann. Chem. Pharm., 72, 213). Rutile containing iron, manganese, and silica was mixed with charcoal and heated in chlorine, and the chlorides were distilled from mercury and potassium. In order to free this product from silicon tetrachloride (which Demoly assumed must have been present in the preparations employed by Rose and Pierre), it was treated with gaseous ammonia and converted by ignition into the nitride. This was then heated in chlorine gas and the chloride was distilled through a system of bulbs connected together by grinding and containing mercury, potassium-amalgam, and potassium. The method of analysis was identical with that of Rose. The following were the results :-

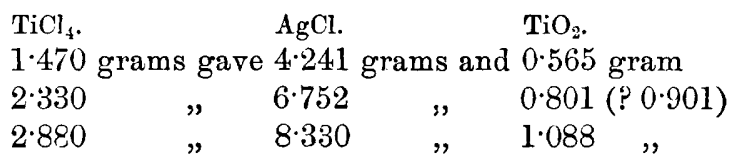

From these numbers, Demoly calculates the composition of titanium tetrachloride as follows :-

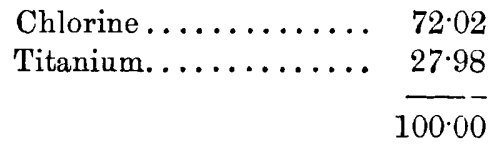

The atomic weights of chlorine and silver adopted in the calculation are not stated, but from the amount of silver chloride furnished by 100 parts of the tetrachloride, Demoly arrives at the value $\mathrm{Ti}=56$.

Demoly, however, appears to have ignored the fact that his anaJytical results afford several ratios from which three independent values for the atomic weight of titanium can be deduced. These values have been calculated by Clarke (loc. cit., 210) with the following results :-

$$
\begin{aligned}
& \text { "From per cent. of } \mathrm{TiO}_{2} \ldots . \quad \mathrm{Ti}=36.063 \pm 0.519 \\
& \text { " AgCl : } \mathrm{TiO}_{2} \ldots \ldots . . \mathrm{Ti}=43.841 \pm 0.350 \\
& \text {, } \mathrm{AgCl}: \mathrm{TiCl}_{4} \ldots \ldots . \mathrm{Ti}=56.386 \pm 0.181 \\
& \text { General mean.... } 52.191 \pm 0.153 "
\end{aligned}
$$

These results enable us to form an idea of the character of the 
product analysed by Demoly. It may be remarked in passing that the precise practical value of calculating their "probable errors" or of taking a "general mean" is not very apparent. The editor of the Annalen (loc. cit.) contents himself with remarking:- "Dieses Resultat (56) weicht so bedeutend von demjenigen ab, welches $H$. Rose and Pierre nach ähnlichem Verfahren erhielten, dass zur Festellung dieses Aequivalente neue Versuche erforderlich sind." This conclusion will be sufficiently obvious from the foregoing statement of what is to be found in the literature of the subject. Professor Clarke (who includes Demoly's numbers in his final mean) concludes that the atomic weight of titanium is "imperfectly determined;" and Meyer and Seubert place it in the list of those elements of which the value is uncertain to within several units.

In framing his arrangement of the elements in accordance with the Periodic Law, Mendelejeff adopted the number 48 as the atomic weight of titanium. A number less than 50 was in fact demanded by the law. Mendelejeff says: "Zugleich ist auf Grund des periodischen Gesetzes anzunehmen dass die Zahlen von Pierre und Demoly höher als die wirklichen sind; denn das Atomgewicht von $\mathrm{Ti}$ muss un ein Geringes bloss höher sein als $\mathrm{Ca}=40$, und kleiner als $\mathrm{V}=51$ und $\mathrm{Cr}=52$. Daher ist die $\mathrm{Zahl}$ von Rose am wahrscheinlichsten, während das Titanchlorid der anderen Forscher geringe, das Atomgewicht erhöhende Verunreinigungen erhalten hat." Mendelejeff, in fact, ventures to suggest that the titanium chloride of the French observers may have contained the chloride of the missing element elasilicium, the atomic weight of which should be about 72, and the oxide of which should be $\mathrm{EsO}_{2}$. "Im äusseren Ansehen, wahrscheinlich auch in den Krystallformen, in den Eigenschaften und in den Reactionen wird dasselbe $\mathrm{TiO}_{2}$ nahe stehen." According to Mendelejeff, elcasilicium chloride, $\mathrm{EsCl}_{\mathbf{4}}$, should be a liquid boiling at about $100^{\circ}$, and might therefore be separated from $\mathrm{TiCl}_{4}$, which boils at about $136^{\circ}$ by fractional distillation; its sp. gr. should be about $1 \cdot 9$, whereas that of $\mathrm{TiCl}_{4}$ is $1 \cdot 76$. "Doch hat ein von mir angestellter Versuch in $\mathrm{TiCl}_{4}$ keinen Gehalt von unter $135^{\circ}$ siedenden Köpern gezeigt." It is equally certain that the chloride of Pierre contained no sensible quantity of any substance boiling at so low a temperature as $100^{\circ}$, and of a sp. gr. of 1.9. He states that his titanium chloride had a constant boiling point of $136^{\circ}$ at $762 \cdot 3$, and that its sp. gr. was $1 \cdot 76088$ at $0^{\circ}$, numbers agreeing closely with those found for this substance in the course of my work on Specific Volumes of Iiquids (Jour. Chem. Soc., Trans., 1880), viz., $136.41^{\circ}$ and 1.76041 at $0^{\circ}$; and as will be shown hereafter, so far as regards the boiling point, with that of the chloride which has served for the present investigation. The chloride employed by Demoly also boiled steadily at $135^{\circ}$, and his 
determinations of the oxide obtained by decomposing the product with water and dilute ammonia, afford direct evidence that his chloride contained no element capable of forming a dioxide, stable on ignition, and of an atomic weight so high as 72 .

The exact determination of the atomic weight of titaninm is rendered difficult by the circumstance that comparatively few compounds of this element exist which are wholly suitable for the purpose. It will have been noticed that all the determinations hitherto published have been made on the tetrachloride-a liquid which is not easily obtained free from hydrochloric acid on account of the readiness with which it suffers alteration in contact with moisture. Moreover, it is liable to contain other chlorides, and possibly also oxychlorides. It has been suggested that the titanofluorides might afford the basis of a series of determinations, but both the preparation and analysis of these bodies offer special difficulties. It is true that Marignac has employed the oxyfluorides and fluorides for the estimation of the atomic weights of niobium, tantalum, and zirconium, but the analytical methods were necessarily somewhat complicated and the source of many possible errors ; thus, in the case of the potassium tantalofluoride the values for Ta differ among themselves by nearly three units.

The compound selected as the basis of an atomic weight determination should be simple in its nature; it should, of course, contain no other element of uncertain atomic weight, and it should be capable of experiencing a definite chemical change by an operation of the simplest possible character. I made a number of trials at the outset of this investigation in the hope of discovering such a method. The conversion of titanium dioxide into the sesquioxide by intense heating in hydrogen suggested itself. Although the accounts given by Rose and Ebelmen of the difficulty of such conversion afforded little hope of success, several attempts were made to effect the reduction, but the loss of weight, even after prolonged ignition in a porcelain tube at the highest temperature of a small blast-gas furnace, was much less than that demanded by theory. Thus, in the experiment in which the greatest amount of reduction occurred, 0.7645 gram of pure titanic oxide, after being heated to whiteness for nearly two hours in a current of dry hydrogen, lost only 0.0276 gram or 3.6 per cent., whereas the theoretical loss should be about 10 per cent. Subsequent and more prolonged heating occasioned a loss of a few additional milligrams. There was obviously no certain indication that complete reduction to the sesquioxide could be obtained.

I next sought to prepare the disulphide according to Ebelmen's method, with a view of roasting it to the dioxide, as originally sug- 
gested by Rose, but although these attempts led to the discovery of certain new sulphides of titanium, they failed to afford a satisfactory process for the determination of the atomic weight of the element, owing mainly to the difficulty of obtaining these bodies in a sufficiently definite form and unmixed with one another.

Attempts to expel the acid radicles, $\mathrm{CO}_{2}$ and $\mathrm{SO}_{3}$, from a number of their salts by titanic oxide, at regulated temperatures, were equally unsatisfactory. It was hoped that the following method might afford a trustworthy basis for a determination. Two platinum crucibles of equal size and weight, each containing about the same weight of recently ignited sodium carbonate, were weighed one against the other. Into one of the crucibles was placed a known quantity of pure titanic oxide, which was carefully mixed with the sodium carbonate by means of a platinum wire. The two crucibles were then placed side by side in a muffle, heated by gas to a bright red heat, and after cooling they were again weighed. From the ratio wt. of $\mathrm{CO}_{2}$ : wt. of $\mathrm{TiO}_{2}=$ mol. wt. $\mathrm{CO}_{2}$ : mol. wt. $\mathrm{TiO}_{2}$, the value of $\mathrm{Ti}$ might be deduced. The idea, however, came to nothing, since it was found that two approximately equal quantities of sodium carbonate when subjected under similar conditions to a bright red heat for equal times, could not be depended upon to suffer the same loss of weight to within 2 or 3 mgrms.

I accordingly reverted to the haloild compounds of titanium, and of these I finally made use of the tetrachloride and tetrabromide. The tetraiodide I deemed unsuitable on account of the slight decomposition to which it is liable at the high temperature of its boiling point. One objection may possibly be raised against the choice of these bodies. It has been repeatedly pointed out that the only certain criterion of the validity of any atomic weight is that it is based upon the concordant results of completely independent methods of analysis. It may be urged that the analyses of bodies of analogous composition, by methods very similar in character, cannot afford such a criterion. I apprehend, however, that in this particular case the objection has very little practical weight. The tetrachloride and tetrabromide of titanium are really very dissimilar bodies; thus, they are not equally susceptible to alteration either by moisture or by the action of oxygen at a high temperature, and they behave very differently on decomposition with water, a matter of considerable practical importance in their analysis. Moreover, the determinations of the exact amount of the halogens in the two bodies are based upon really independent methods, and the values of $\mathrm{Ti}$ which they afford are referred to atomic weights which are themselves obtained by methods equally independent. Indeed, as is well known, there are few atomic weights of which the values are known to such a high degree of precision as 
those of silver and the halogens. The determination of the amount of titanic oxide yielded by known weights of the chloride and bromide not only offers the possibility of a second and independent value, but also affords a stringent check upon the purity of these compounds. And lastly, the ratio of the weight of silver used to that of the silver chloride and silver bromide obtained, affords an additional guarantee both of the purity of the silver and of the absence of coprecipitated titanic oxide.

Before describing the modes of preparing and analysing the chloride and bromide of titanium, it may be desirable to give some details respecting the method of weighing and the preparation of the silver employed.

Method of Weighing. - The balance was a short beamed instrument of the Bunge pattern made by Oertling. It was carefully adjusted, and its sensibility under varying loads ascertained by the method of vibrations. The results were as follows:-

Load in grams. $\quad d$ in mgrms.

Load in grams.

$d$ in mgrms.

\begin{tabular}{rl|rl}
0 & 0.16 & 20 & $0 \cdot 246$ \\
2 & $0 \cdot 19$ & 50 & $0 \cdot 304$ \\
5 & 0.196 & 100 & 0.395 \\
10 & 0.217 & &
\end{tabular}

During the day's work the position of equilibrium of the beam of this instrument was subject to a steady progressive alteration, as if the two arms expanded unequally, or as if one became warped during the day, but assumed its original form when the balance was allowed to remain at rest. The extent of the variation was too small to affect the results to any appreciable amount; in practice, the effect was eliminated by taking the position of rest before and after the weighing. The degree of variation may be seen from the accompanying example, taken from a large number of similar observations, made with a view of ascertaining the cause of the phenomenon :-

Oct. 17th, 1881.

\begin{tabular}{lc|lc} 
Time. & Position of rest. & Time. & Position of rest. \\
10 A.M. & $12 \cdot 68$ & 1 P.M & $11 \cdot 23$ \\
11 ,. & $12 \cdot 22$ & 2, & $10 \cdot 65$ \\
12 noon & $11 \cdot 70$ & 3.5 P.M. & $10 \cdot 22$ \\
& & 3.35, & $10 \cdot 10$
\end{tabular}

The balance case in these observations, as in all subsequent weighings, was shielded from draughts by screens : thermometers placed on each side of the case indicated no difference in temperature. The temperature of the room seldom varied more than $5^{\circ}$ during the day, and on some days the variation was much less. No connection was 
noticed between the extent of the variation of temperature and the degree of alteration in the position of rest. On the conclusion of the foregoing readings, the balance case was placed at right angles to its former position, and it was allowed to remain at rest for about 18 hours, when the following readings were taken:-

Oct. 18th, 1881 .

$\begin{array}{lc}\text { Time. } & \text { Position of rest. } \\ 10 \cdot 15 \text { A.M. } & 12 \cdot 27 \\ 11 & 11 \cdot 83 \\ 11 \cdot 50 & 11 \cdot 16 \\ 12 \text { noon } & 11 \cdot 08 \\ 2 \text { P.M. } & 9 \cdot 81\end{array}$

During the night, the balance came back to about its original position of rest; as the day advanced, the position of equilibrium gradually altered, as if the left arm had a higher coefficient of expansion than the other, or as if a constant current of air bad been set up in the balance case, tending to make one pan appear lighter than the other. This progressive alteration in the position of the zero has been noticed by others : it is particularly mentioned by Miller in his "Determination of the Standard Pound," and I am informed by Professor Poynting that it was constantly observed by him in the course of his observations on the determination of the mean density of the earth by means of the balance (Proc. Roy. Soc., 1878).

The weights employed were of strongly gilded brass : they were made by Staudinger of Giessen. They were compared among themselves by the method of vibrations, one of the 10-gram weights being taken as the standard. The relative values may be given here as showing the degree of accuracy to which weights of good construction are ordinarily adjusted:-

$$
\begin{aligned}
& \mathrm{D}=\text { denomination of weight } \\
& \mathrm{W}=\text { true relative weight. }
\end{aligned}
$$

\begin{tabular}{c|c|c|c|c|c|c|c}
\hline $\mathrm{D}$. & W. & D. & W. & D. & W. & D. & W. \\
\hline 100 & $99 \cdot 99906$ & 5 & $5 \cdot 00003$ & $0 \cdot 5$ & $0 \cdot 50000$ & $0 \cdot 02$ & $0 \cdot 02003$ \\
50 & $49 \cdot 99938$ & 2 & $2 \cdot 00011$ & $0 \cdot 2$ & $0 \cdot 19994$ & $0 \cdot 01$ & $0 \cdot 01000$ \\
20 & $19 \cdot 99978$ & 1 & $0 \cdot 99997$ & $0 \cdot 1$ & $0 \cdot 09999$ & $0 \cdot 01$ & $0 \cdot 01003$ \\
10 & $10 \cdot 00000$ & $1^{\prime}$ & $0 \cdot 99996$ & $0 \cdot 1^{\prime}$ & $0 \cdot 10001$ & $0 \cdot 01^{*}$ & $\begin{array}{l}0 \cdot 010036 \\
0 \cdot 010002\end{array}$ \\
$10^{\prime}$ & $10 \cdot 00007$ & $1^{\prime \prime}$ & $0 \cdot 99996$ & $0 \cdot 05$ & $0 \cdot 04999$ & $0 \cdot 01^{*}$ \\
\end{tabular}

Whenever practicable the correction for displacement of air, which at best is a very uncertain correction, was obviated or rendered as small as possible by using as a tare a vessel of precisely the same size 
and character as that employed to contain the substance weighed. Both vessels were treated in exactly the same manner: thus, if one vessel was heated to redness or placed under a desiccator, the tare was similarly treated and at the same time. In this way, the uncertainty of weight arising from the condensation of air or moisture on the surface of the vessel, or the errors which might be due to the varying density of the air from differences in humidity, were eliminated.

The corrections employed for reduction to a standard atmosphere were as follows :-

\begin{tabular}{|c|c|c|c|}
\hline \multicolumn{4}{|c|}{ Per gram of titanium tetrachloride } \\
\hline " & tetrabromide & 0.000333 & " \\
\hline$"$ & dioxide .... & 0.000133 & \\
\hline$"$ & silver chloride ..... & 0.000070 & \\
\hline$"$ & , bromide ...... & 0.000067 & \\
\hline , & metallic silver . . . . . & nil. & \\
\hline
\end{tabular}

Preparation of Metallic Silver.-A solution of the so-called "triple crystallised" silver nitrate of commerce was mixed with excess of dilute hydrochloric acid, and the precipitate was repeatedly boiled with strong nitric acid, washed, dried, and reduced by fusion with a mixture of sodium and potassium carbonates. The kutton of silver was well washed and dissolved in nitric acid, the liquid was diluted to about 7 litres and mixed with a dilute solution of pure hydrochloric acid, and the vessel was set aside in a dark place. The silver chloride was treated with dilute hydrochloric acid, and repeatedly digested with aqua regia, and lastly washed with water. It was then transferred to a silver dish and boiled with a solution of pure caustic soda and milk-sugar until a portion of the precipitate was found to be wholly soluble in nitric acid. The grey precipitate of finely-divided silver was well washed and digested with dilute ammonia to remove any undecomposed silver chloride which might possibly remain; on acidulating the decanted solution with nitric acid not the faintest opalescence was perceived. The silver was next washed with a little dilute sulphuric acid, and finally with distilled water and fused on a support of "brasqued" lamp-black. The fusion was effected at the lowest possible temperature, and care was taken so to regulate the current of air that no excess of oxygen was present in the flame; as the buttons cooled they were surrounded by a faintly luminous flame in order to minimise the chance of the occlusion of oxygen. I have not thought it necessary to attempt to determine the amount of oxygen which might be occluded; the quantity, even if as large as that found by Mallet in the silver employed by him in his determination of the atomic weight of aluminium (Phil. Trans., 1880, 3, 1020) would have no appreciable influence on the result. Mallet only obtained from 30 
to 35 c.c. of oxygen per kilo. of silver, an amount far less than that obtained by Dumas, who found as much as 160 or 170 c.c.

I am reasonably certain that the metallic silver employed in my determinations was of a high degree of purity, but I do not imagine that it was purer than that prepared by Mallet and by Stas by the same methods. I have assumed therefore that 1 gram of the metal contained 0.99995 gram of real silver.

\section{Titanium Tetrachloride.}

About a kilogram of titanium tetrachloride was prepared by igniting precipitated titanic oxide (known to be free from iron and silica) mixed with lampblack which had been previously heated to redness in chlorine, in a stream of chlorine gas. The product was boiled for some time to expel excess of chlorine, and was then distilled: it practically all came over between $135^{\circ}$ and $136^{\circ}$. It was again distilled in an atmosphere of dry nitrogen gas, when the following observation of its boiling point was made :-

$$
\mathrm{T}=135 \cdot 78^{\circ} ; t=24 \cdot 1^{\circ} ; \mathrm{N}=32 ; \operatorname{Bar} .754 .5 \text { at } 10 \cdot 1^{\circ} \text {. }
$$

These numbers give $136^{\circ} \cdot 35$ at $753.28 \mathrm{~mm}$. for the corrected boiling point. Previous observations (Trans., 1880, 329) gave $136.41^{\circ}$ at $760 \mathrm{~mm}$.

In order to collect portions for analysis without exposure to air, the arrangement shown in Fig. 1, p. 120, was employed.

The air in the apparatus was first removed by a current of dry carbon dioxide, and this gas was then displaced by dry nitrogen. The titanium tetrachloride was transferred to the distilling flask from the bottles in which it had been preserved by replacing the stopper of the bottle by a cork carrying two tubes, one of which ended at the under side of the cork, whilst the other reached to the bottom of the bottle. This latter tube was, outside the bottle, bent twice at right angles, so that the longer limb could be inserted through a perforated cork in the distilling flask. The tetrachloride was then driven over into the flask by the pressure of dry air. The liquid was next distilled, the first portion passing direct into the bottle $\mathrm{B}$, the cock $d$ being open. When about one-third of the liquid had passed over, $d$ was turned, and the bottle $B$ replaced by a small distilling flask. The cock was again opened and the $\mathrm{TiCl}_{4}$ allowed to flow into the flask. The distillation was proceeded with until the small distilling flask was almost full. The process was then stopped, and the large distilling flask was replaced by the smaller flask, the bottle $\mathrm{B}$ being again placed in its original position. A current of dry nitrogen was again passed through the whole apparatus, and the 
distillation was resumed. C was first rinsed out by allowing small portions of the distillate to collect in it and then running it off into

Frg. 1.

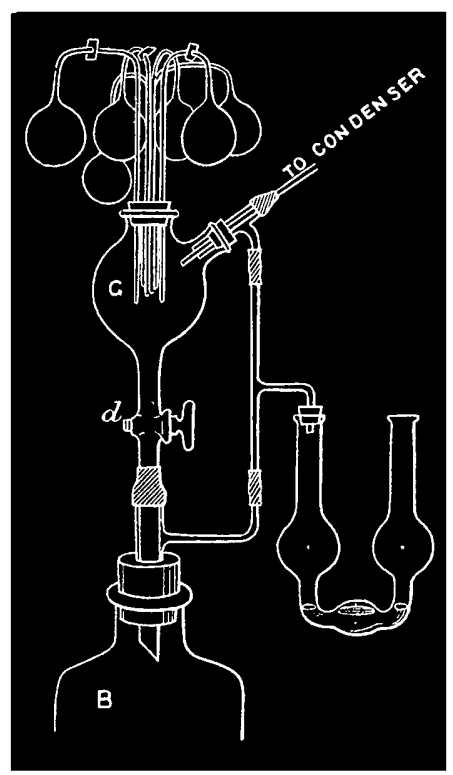

B by turning $d$. When about one-third of the chloride had distilled over, $d$ was finally closed, and when a sufficient quantity had collected in $\mathrm{C}$ the distillation was stopped. The weighed bulbs were now filled by warming and allowing the tetrachloride to pass into them, and each was sealed off in turn at the bend by the blowpipe flame. The detached tubes were carefully cleaned, dried, and weighed with the buibs belonging to them.

Titanium tetrachloride is violently decomposed by water, and the evolution of heat is so great that a considerable proportion of the dioxide is precipitated as the so-called metatitanic acid. If the solution be not too dilute, and especially if nitric acid be present, the metatitanic acid will gradually dissolve, and eventually the liquid becomes perfectly clear. If solution of silver nitrate be now added, the precipitate of silver chloride which is formed is free from coprecipitated titanic oxide, provided the nitric acid be present in sufficient excess. The rehydration of the titanic oxide and its subsequent solution require some time. A bulb containing 5.6023 grams of pure titanium tetrachloride broken in 35 c.c. of cold distilled water, gave a solution 
of about the opacity of milk, which, with occasional shaking, became perfectly clear in about 40 hours. The liquid remained clear, even when heated to about $80^{\circ}$; at $87^{\circ}$ it was milky, and at about $90^{\circ}$ ar $91^{\circ}$ the greater part of the titanic oxide was precipitated. When mixed with an equal bulk of water, the solution was only slightly turbid at $85^{\circ}$, and required to be heated to $95^{\circ}$ or $96^{\circ}$ before the oxide was precipitated. The effect of the addition of nitric or hydrochloric acid in retaining the hydrate in solution is very marked. Thus, when an equal bulk of strong hydrochloric acid was added to the solution, no precipitate was noticed until at about $98^{\circ}$, and even then it was very faint; on heating to about the boiling point $\left(109^{\circ}\right)$, the turbidity was only very slightly increased.

Titanic acid is known to be soluble in solution of tartaric acid. I found, however, that nothing was gained by decomposing the tetrachloride in solutions of this acid, or by adding the acid to the turbid liquid resulting from the action of water. Indeed the tartaric acid seemed to retard rather than accelerate the solution of the oxide.

If a bulb containing titanium tetrachloride be broken under solution of silver nitrate containing free nitric acid, the precipitated silver chloride is found after a few days to be perfectly free from titanic oxide.

These facts are of importance as tending to simplify the method of analysing the chloride. The clarification of the turbid liquid by standing, and the fact that the precipitated silver chloride is free from titanic oxide, altogether obviate the necessity of removing the titanic oxide previous to the addition of the silver nitrate solution. This is the more fortunate, since titanic hydrate precipitated by ammonia is filtered and washed only with some difficulty and patience.

\section{Series I. $\mathrm{TiCl}_{4}: 4 \mathrm{Ag}$.}

The method of determination in this series was as follows:-The bulb containing the known quantity of the tetrachloride was placed in a well-stoppered bottle together with about 150 c.c. of pure water; the stopper was then firmly tied down, a small wedge being inserted under the string to tighten the fastening, and by a smart jerk the bulb was broken against the side of the bottle. The reaction is very violent, but if care be taken in selecting the bottle and in fastening down the stopper, the decomposition may be safely effected. The turbid liquid was set aside for a few days to clarify. In the meantime, a quantity of the silver slightly less in amount than would be required to combine with the chlorine-on the assumption that the atomic weight of titanium is 50 -was weighed out, placed in a litre bottle, also fitted with a well-ground stopper, and dissolved at a gentle 
heat, and as slowly as possible, in a slight excess of nitric acid of sp. gr. 1.21, the stopper being from time to time lifted so as to allow of the escape of the nitrous fumes. The solution of the silver nitrate was then heated to expel the dissolved gas, which was driven from the bottle by a gentle current of washed air, a quantity of distilled water was added, and thereafter the clear solution of the tetrachloride. The fragments of glass in the small bottle were repeatedly washed by decantation, and the liquid, after standing, added to the main bulk of the solution. The glass was then dried and weighed as a check on the determination of its weight in the first instance. The differences thus found were very small; in no case would they have affected the result in the second place of decimals. The admixture of the solutions of the tetrachloride and silver nitrate was made in a room illuminated by yellow or orange light. The turbid liquid was then briskly shaken until it became clear, and successive small portions of a solution of silver nitrate containing 0.001072 gram silver per cubic centimetre were added until no further turbidity could be perceived. The operation was carried out in substantially the same manner as that described by Stas, the bottles being placed in black cloth bags during the time occupied by the subsidence of the silver chloride.

Table I contains the results thus obtained :-

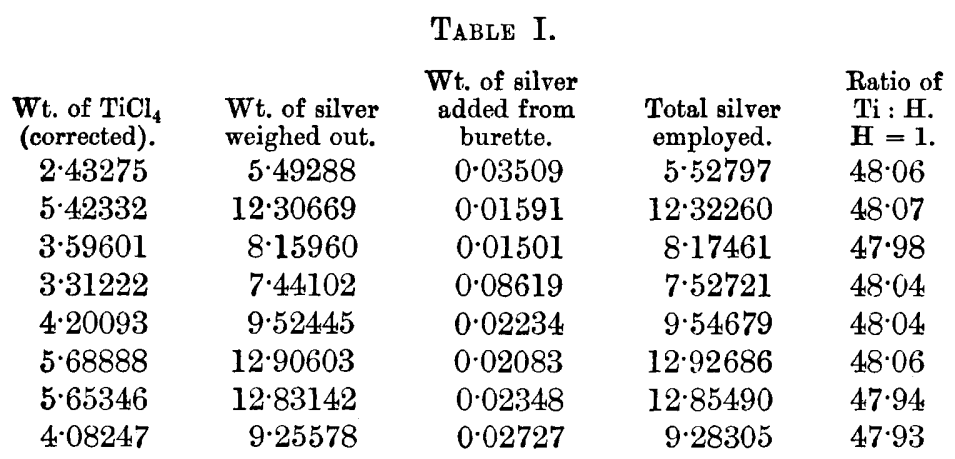

\section{Series II. $\mathrm{TiCl}_{4}: 4 \mathrm{AgCl}$.}

As a further check, and with a view of obtaining an additional value for $\mathrm{Ti}$ from the ratio of $\mathrm{TiCl}_{4}$ to $\mathrm{AgCl}$, the precipitated silver chloride was collected and weighed.

Two porcelain crucibles of 70 c.c. capacity were weighed one against the other by the method of vibrations; one of these was to contain the silver chloride, the other served as a tare. In order to collect the chloride the method of "reverse filtration" was employed. The silver chloride was transferred to the weighed crucible by decan- 
tation, the solution of titanic oxide and the washing-water being removed by aspiration through a small disc of filter-paper about $13 \mathrm{~mm}$. radins placed upon the perforated base of a platinum "rose," disc and "rose" being previously weighed with the crucible. The arrangement is seen in Fig. 2.

FIG. 2.

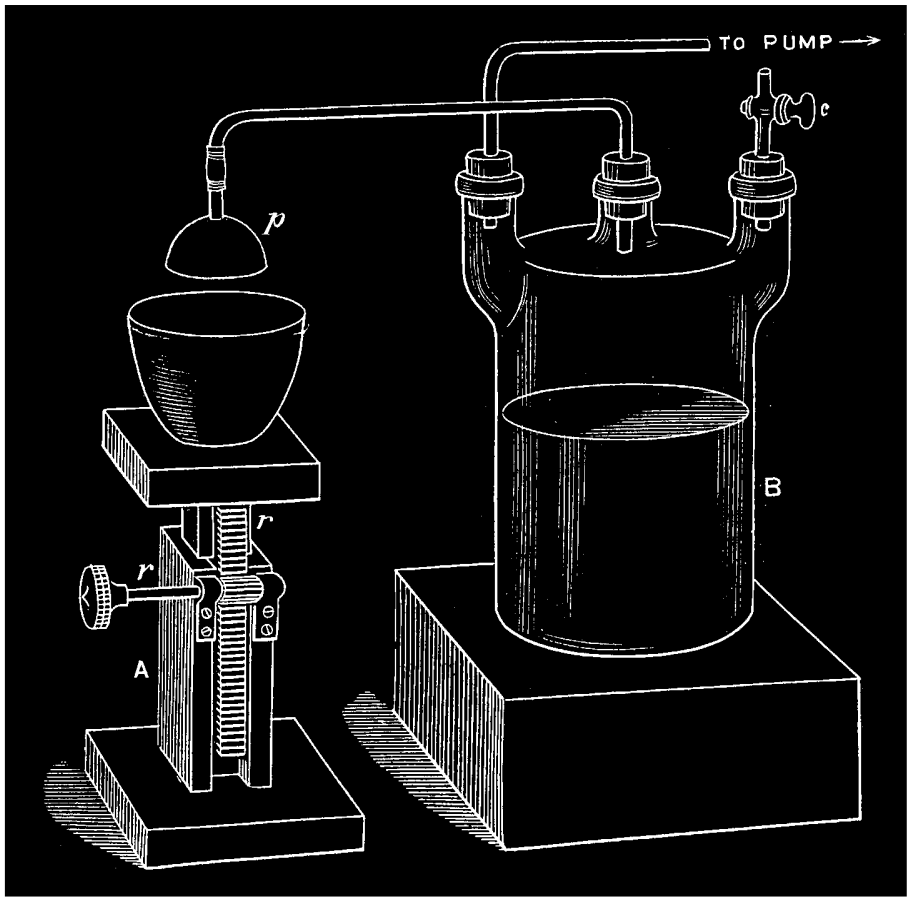

$A$ is a small elevating table, the top of which can be raised or lowered by the rack and pinion, $r r$, so that the "rose," $p$, with the adhering paper disc, may be placed at any required depth within the crucible or withdrawn entirely from it. The "rose" is attached by a piece of narrow flexible rubber tubing to a glass tube leading to the three-necked bottle B. The " rose" can when necessary be placed at right angles to the position shown by hanging it, without detaching it from the rubber tube, upon a glass hook on the tube above. The diminution of pressure within $B$ is effected by the action of a waterjet pump. At $c$ is a glass stopcock; by turning it the air can be permitted to flow into $\mathbf{B}$ and the aspirating action of the pump immediately arrested. The method of using the arrangement requires but 
little explanation. The small disc of paper, which should be cut with a sharp pair of scissors so as to leave a clean edge, is placed against the "rose," moistened with water, and accurately adjusted, so that the periphery of the paper is concentric with the rim of the "rose." The cock $c$ is closed, and the water-pump set in action so as to draw up the paper against the face of the platinum "rose." The crucible is then nearly filled with the clear solution of the titanic oxide, and without stopping the action of the pump the "rose" and paper are immersed in the liquid, which is drawn over into $\mathrm{B}$, the crucible being replenished from time to time with fresh portions of the solution. 'The chloride, from which the solution is drained off as far as possible, is then treated with successive small quantities of dilute nitric acid, thoroughly washed with water, and transferred to the crucible. The liquid in the crucible may be drawn off until the chloride is almost dry. The "rose" with its adhering paper is then detached from the tube, allowed to fall on the cake of the chloride, and the whole is dried in the steam-bath, when the crucible is transferred to the air-bath and heated for some hours at about $160^{\circ}$ until its weight is constant. Direct experiment has shown that silver chloride can be thoroughly dried at this temperature if heated for a sufficient length of time. On no occasion, after the weight had become constant, did the chloride suffer a diminution of weight by fusion that would affect the second decimal place in the result; usually the difference was almost inappreciable.

The method of reverse filtration was originally devised by Professor Carmichael, of Bowdoin College (Zeits. f. Chemie, N.F., 6, 481; Fres. Zeits., 10, 82), but the arrangement of the apparatus used by me is practically the same as that described by Professor J. P. Cooke (Proc. Amer. Acad. Arts and Sciences, 12, 124), and employed by him in his determination of the atomic weight of antimony (loc. cit., 13, 1).

The results obtained by weighing the silver chloride are seen in Table II.

TABLE II.

$\begin{array}{ccc}\begin{array}{c}\text { Wt. of } \mathrm{TiCl}_{4} \\ \text { (corrected). }\end{array} & \begin{array}{c}\text { Wt. of } \mathrm{AgCl} \\ \text { (corrected). }\end{array} & \begin{array}{c}\text { Ratio } \mathrm{Ti}: \mathrm{H} . \\ \mathrm{H}=1 .\end{array} \\ 3 \cdot 31222 & 10 \cdot 00235 & 47 \cdot 99 \\ 4 \cdot 20093 & 12 \cdot 68762 & 47 \cdot 97 \\ 5 \cdot 68888 & 17 \cdot 17842 & 48 \cdot 00 \\ 5 \cdot 65346 & 17 \cdot 06703 & 48 \cdot 05 \\ 4.08247 & 12 \cdot 32442 & 48 \cdot 05\end{array}$

The weighed chloride was then digested with ammonia in order to ascertain its freedom from coprecipitated titanic oxide: in no in- 
stance was this detected. The most stringent evidence of the absence of this substance is, however, afforded by a comparison of the amount of the silver chloride found with the known weight of the silver used in the first series. The total weight of the silver chloride obtained was $69 \cdot 25983$ grams : it was formed from $52 \cdot 13881$ grams of silver.

$$
\text { Now } 52 \cdot 13881: 69 \cdot 25983=\mathrm{Ag}: \mathrm{AgCl}=1: 1 \cdot 3284 \text {. }
$$

Stas found from seven experiments in which, in the aggregate, $969 \cdot 3548$ grams of silver were found to give $1287 \cdot 7420$ grams of silver chloride, that-

$$
\mathrm{Ag}: \mathrm{AgCl}=1: 1 \cdot 32845 .
$$

The two ratios, it will be seen, are almost identical.

\section{Series III. $\mathrm{TiCl}_{4}: \mathrm{TiO}_{2}$.}

In these experiments the weighed portions of the tetrachloride contained in glass bulbs were decomposed by water in well-stoppered bottles and the solution decanted into a weighed platinum dish of 60 c.c. capacity. The dish was supported on a glass rim over the water-bath, and during the evaporation of the titanic oxide solution it was covered with a large glass shade exactly as in the process of evaporation in Frankland's method of water analysis. When the residue was nearly dry, the dish was filled up with a dilute solution of ammonia, a similar amount of ammonia solution, together with the same quantity of distilled water which had been used in decomposing the tetrachloride and decanting the solution, being evaporated down in the tare. The addition of ammonia to the dried titanic oxide was found to be absolutely necessary to complete the decomposition of the chloride; when the strong hydrochloric acid solution of the oxide is evaporated to dryness and heated, a notable quantity of titanium escapes either as oxychloride or tetrachloride, and a portion is found to have sublimed on the platinum covering of the crucible. No such sublimate is formed after the addition of ammonia.

Titanic oxide is too hygroscopic to be weighed in the ordinary way with free exposure to air. Even after prolonged and intense heating, whereby it shrinks very considerably in bulk and becomes granular, it still absorbs appreciable quantities of moisture if freely exposed to the air. In weighing it, therefore, the crucible containing the titanic oxide was placed under a cover made by inverting a light glass crystallising dish on a thin piece of polished plate-glass; between the plate and the dish was a narrow circular strip of thin sheet caoutchouc, against which the dish was pressed by an indiarubber band. The cover thus made fitted perfectly air-tight, and the 
titanic oxide might be allowed to stand for hours on the pan of the balance without any perceptible increase of weight. In order to guard against any change of weight arising from oxidation of the rubber or from its hygroscopic nature, the cover was weighed immediately before and immediately after the determination of the weight of the titanic oxide.

Table III contains the results.

TABLE III.

$\begin{array}{ccc}\begin{array}{c}\text { Wt. of } \mathrm{TiCl}_{4} \\ \text { (corrected). }\end{array} & \begin{array}{c}\text { Wt. of } \mathrm{TiO}_{2} \\ \text { (corrected) }\end{array} & \begin{array}{c}\text { Ratio Ti }: \mathrm{H} . \\ \mathrm{H}=1 .\end{array} \\ 6 \cdot 23398 & 2 \cdot 62825 & 4 \cdot \cdot 93 \\ 8 \cdot 96938 & 3 \cdot 78355 & 4800 \\ 10 \cdot 19853 & 4 \cdot 30128 & 47 \cdot 99 \\ 6 \cdot 56894 & 2 \cdot 77011 & 47 \cdot 96 \\ 8 \cdot 99981 & 3 \cdot 79575 & 47 \cdot 98 \\ 8 \cdot 32885 & 3 \cdot 51158 & 47 \cdot 94\end{array}$

\section{Titanium Tetrabromide.}

This compound was first prepared by Mr. Francis B. Duppa, who obtained it by passing bromine vapour over a strongly heated mixture of titanic oxide and charcoal (Proc. Roy. Soc., 8, 42). I find that it can be readily prepared by the action of hydrobromic acid gas upon the tetrachloride.

About 350 grams of titanium tetrachloride were placed in a distilling flask connected with an upward condenser and heated to a few degrees below its boiling point, and a steady stream of hydrobromic acid gas, produced by the action of bromine upon a mixture of amorphous phosphorus and water, was led into it. The hydrobromic acid gas was freed from vapour of bromine by passing through a $\mathbf{U}$-tube filled with fragments of glass and amorphous phosphorus, and was dried by passing through a second $U$-tube containing calcium chloride. To ensure the complete displacement of the chlorine in the tetrachloride, the passage of the hydrobromic acid was continued for about three days. As the subsequent analyses will show, the product was perfectly free from chlorine.

With respect to the physical properties of titanium tebrabromide, I have but little to add to the description ulready given by $\mathrm{Mr}$. Duppa. It is a beautifully crystalline substance of a dark-yellow or orange colour, melting at about $40^{\circ}$, and boiling at $229^{\circ}$ (uncorr.). It is very hygroscopic, and is readily decomposed by water with the evolution of comparatively little heat and with the production of a perfectly clear solution. 
To collect it for the purpose of analysis, an arrangement very similar to that used in the case of the chloride was employed. About 400 grams of the recently distilled tetrabromide were placed in a distilling flask connected with a short wide tube leading to the vessel (Fig. 1), in the upper neck of which were placed a number of thin glass bulbs, previously weighed, and identified by means of attached labels of thin sheet zinc, marked with the number of the bulbs. (The labels were not weighed with the bulbs.) About onethird of the tetrabromide was then distilled over into $\mathrm{C}$, and allowed to flow into the bottle. If the bromide showed any signs of solidification it could be readily melted by gently warming the ressel $\mathrm{C}$. Another third portion of the tetrabromide was then distilled over and strongly heated when in $\mathrm{C}$, so as to prevent any chance of its solidifying in the capillary tubes of the bulbs. These were then heated and filled in exactly the same manner as in the case of the chloride.

\section{Series $I V . \quad \mathrm{TiBr}_{4}: 4 \mathrm{Ag}$.}

Weighed portions of the tetrabromide were decomposed by water, and the clear solution treated in precisely the same manner as in Series I. As no metatitanic acid was formed, the liquid could be immediately mixed with the solution of the known weight of the silver.

The addition of the silver solution was made in a room illuminated by yellow light, and the determination of the point of final precipitation effected as described on p. 122.

The results are contained in Table IV.

\section{TABLE IV.}

\begin{tabular}{|c|c|c|c|c|}
\hline $\begin{array}{c}\text { Wt. of } \mathrm{TiBr}_{4} \\
\text { (corrected). } \\
2.854735\end{array}$ & $\begin{array}{c}\text { Wt. of silver } \\
\text { weighed out. } \\
3 \cdot 33148\end{array}$ & $\begin{array}{c}\text { Wt. of silver } \\
\text { added from } \\
\text { burette. } \\
0.01779\end{array}$ & $\begin{array}{l}\text { Total silver } \\
\text { employed. } \\
3.34927\end{array}$ & $\begin{array}{c}\text { Ratio of } \\
\mathrm{Ti}: \mathrm{H} . \\
\mathrm{H}=\mathbf{1} . \\
48 \cdot 04\end{array}$ \\
\hline $3 \cdot 120848$ & $3 \cdot 64302$ & 0.01820 & $3 \cdot 66122$ & $48 \cdot 06$ \\
\hline $4 \cdot 731118$ & $5 \cdot 52498$ & 0.02589 & $5 \cdot 55097$ & 48.02 \\
\hline 6.969075 & $8 \cdot 16733$ & 0.00912 & $8 \cdot 17645$ & $48 \cdot 03$ \\
\hline $6 \cdot 678099$ & $7 \cdot 82424$ & 0.01069 & $7 \cdot 83493$ & $48 \cdot 04$ \\
\hline
\end{tabular}

Series $V . \mathrm{TiBr}_{4}: 4 \mathrm{AgBr}$.

The precipitated silver bromide was filtered off in the manner described in Series II (p. 122), dried at $160^{\circ}$, and weighed. The results are seen in Table $V$. 


$\begin{array}{ccc}\begin{array}{c}\text { Wt. of } \mathrm{TiBr}_{4} \\ \text { (corrected). }\end{array} & \begin{array}{c}\text { Wt. of } \mathrm{AgBr} \\ \text { (corrected). }\end{array} & \begin{array}{c}\text { Ratio of } \mathrm{Ti}: \mathrm{H} . \\ \mathrm{H}=1 .\end{array} \\ 3 \cdot 120848 & 6 \cdot 375391 & 47 \cdot 95 \\ 4 \cdot 731118 & 9 \cdot 663901 & 47 \cdot 99 \\ 6.969075 & 14 \cdot 227716 & 48 \cdot 19 \\ 6.678099 & 13.639956 & 48 \cdot 02\end{array}$

The total amount of the silver bromide obtained in Series $V$ was 43.90694 grams: it was formed from 25.22357 grams of metallic silver employed in the preceding series.

Now $25 \cdot 22357: 43 \cdot 90694=\mathrm{Ag}: \mathrm{AgBr}=1: 1 \cdot 7407$.

Marignac (Bibl. Univ. Genève, 46, 360) found from three experiments in which, in the aggregate, 60.120 grams of silver afforded 104.648 grams of silver bromide, that-

$$
\mathrm{Ag}: \mathrm{AgBr}=1: 1 \cdot 74077 \text {. }
$$

Stas (Nouv. Rech., p. 158, 1865) obtained in five experiments $459 \cdot 1681$ grams of silver bromide from $263 \cdot 7669$ grams of silver. Hence-

$$
\mathrm{Ag}: \mathrm{AgBr}=1: 1 \cdot 74081 .
$$

The ratio deduced from my experiments agrees satisfactorily with that resulting from the observations of Stas and Marignac.

\section{Series VI. $\mathrm{TiBr}_{4}: \mathrm{TiO}_{2}$.}

The weighed portions of the tetrabromide contained in bulbs were broken under water as in Series III, and the liquid evaporated to dryness, the residue treated with ammonia solution, and strongly heated. It was found impossible to make use of platinum dishes, as these were attacked by the free bromine evolved from the concentrated solution of hydrobromic acid. The evaporation was accordingly made in large porcelain crucibles, a quantity of water and ammonia equal to the amounts employed in the decomposition of the bromide being evaporated in a precisely similar crucible used as a tare, and both crucibles were heated side by side in the same muffle, and otherwise treated in exactly the same way. The results of three experiments are seen in Table VI.

\section{TABLE VI.}

$\begin{array}{ccc}\begin{array}{l}\text { Wt. of } \mathrm{TiBr}_{4} \\ \text { (corrected). }\end{array} & \begin{array}{c}\text { Wt. of } \mathrm{TiO}_{2} \\ \text { (corrected). }\end{array} & \begin{array}{c}\text { Ratio of Ti }: \mathrm{H} . \\ \mathbf{H}=1 .\end{array} \\ 6.969730 & 1.518722 & 48 \cdot 08 \\ 8.836783 & 1.923609 & 47.97 \\ 9.096309 & 1.979513 & 47.94\end{array}$


All the experiments which were made either for the estimation of the bromine or chlorine, or for that of the titanic oxide yielded by the decomposition of the tetrabromide or tetrachloride, are given with the exception of four; one of these was made upon a small quantity of material and was considered as preliminary; the other three miscarried.

\section{Calculation of the Results.}

In order to enable an opinion to be formed as to the agreement among the several observations, the value of $\mathrm{Ti}$ has been calculated from each experiment. But probably the most accurate values of the atomic weight are to be deduced from the aggregate weights of the tetrachloride, silver, silver chloride, and titanic oxide; and of the tetrabromide, silver, silver bromide, and titanic oxide, respectively. It is to be presumed that the employment of large quantities of material tends to increase the accuracy of the results; hence the in. fluence of the larger quantities is directly felt by calculating the final values from the aggregate weights in the several series instead of merely taking the means of the several observations.

I assume with Lothar Meyer and Seubert that the most probable ratios of $\mathrm{Ag}, \mathrm{Cl}, \mathrm{Br}, \mathrm{O}$, and $\mathrm{H}$ are as follows :-

$$
\begin{aligned}
& \mathrm{Ag}=6 \cdot 7456 \\
& \mathrm{Cl}=2 \cdot 21586 \\
& \mathrm{Br}=4 \cdot 99721 \\
& \mathrm{O}=\mathrm{l} \\
& \mathrm{H}=0.06265 .
\end{aligned}
$$

Adopting these numbers, we may thus summarise the results of the various observations :-

$$
\begin{aligned}
& \text { Series } I \text { ( } 8 \text { experiments). } \\
& \mathrm{TiCl}_{4}: 4 \mathrm{Ag}=34 \cdot 39004: 78 \cdot 16399 \\
& \mathrm{TiCl}_{4}: \mathrm{O}=11.8715: 1 \\
& \text { Ti: } \mathrm{O}=3.0081: 1 \\
& \mathrm{Ti}: \mathrm{H}=48.014: 1 \\
& \mathrm{TiCl}_{4}: 4 \mathrm{AgCl}=22 \cdot 93796: 69 \cdot 25983 \\
& =1.32475: 4 \\
& \mathrm{TiCl}_{4}: \mathrm{O}=11 \cdot 8716: 1 \\
& \mathrm{Ti}: \mathrm{O}=3.0082: 1 \\
& \mathrm{Ti}: \mathrm{H}=48.016: 1
\end{aligned}
$$

VOL. XLVII. 
S'eries III (6 experiments).

$$
\begin{aligned}
\mathrm{TiCl}_{4}: \mathrm{TiO}_{2} & =4.9 \cdot 29948: 20 \cdot 79032 \\
& =2 \cdot 37124: 1 \\
\mathrm{Ti}: \mathrm{O} & =3 \cdot 0053: 1 \\
\mathrm{Ti}: \mathrm{H} & =47.969: 1
\end{aligned}
$$

Series IV (5 experiments).

$$
\begin{array}{cl}
\mathrm{TiBr}_{4}: 4 \mathrm{Ag} & =24 \cdot 35387: 28.57284 \\
& =3.40937: 4 \\
\mathrm{TiBr}_{4}: \mathrm{O} & =22 \cdot 99827: 1 \\
\mathrm{Ti}: \mathrm{O} & =3 \cdot 0094: 1 \\
\mathrm{Ti}: \mathrm{H} & =48.031: 1
\end{array}
$$

Series V (4 experiments).

$$
\begin{aligned}
\mathrm{TiBr}_{4}: 4 \mathrm{AgBr} & =21 \cdot 49914: 4.3 \cdot 90696 \\
& =1 \cdot 95861: 4 \\
\mathrm{TiBr}_{4}: \mathrm{O} & =22 \cdot 99960: 1 \\
\mathrm{Ti}: \mathrm{O} & =3.0107: 1 \\
\mathrm{Ti}: \mathrm{H} & =48.057: 1
\end{aligned}
$$

Series VI (3 experiments).

$$
\begin{aligned}
\mathrm{TiBr}_{4}: \mathrm{TiO}_{2} & =24.90283: 5.42184 \\
& =4.59311: 1 \\
\mathrm{Ti}: \mathrm{O} & =3.0065: 1 \\
\mathrm{Ti}: \mathrm{H} & =47.989: 1
\end{aligned}
$$

It is of course possible that these various values do not merit the same degree of confidence, but I am unable on any precise à priori grounds to apportion the relative weights which should be attributed to them in taking a final mean. Each set of determinations has its special difficulties, and is liable to errors of which we have no method of assessing the numerical value. Titanium tetrachloride is very susceptible to change in contact with moisture, and is generally more difficult to work with than the bromide, and, as is well known, the end-point in the precipitation by Gay-Lussac's method cannot be so precisely hit in the case of chlorides as in that of bromides. Series II and V may be affected by the relative solubilities of the silver salts. On the other hand, the tetrabromide is rather more difficult of preparation in a pure state than the chloride. At first sight, the determinations of the oxide, yielded by the decomposition of the two bodies, might be deemed to afford the most trustworthy basis, as the method employed is the simplest in principle; but titanic oxide is extremely difficult to dehydrate, and rehydrates itself with rapidity in contact with moist air. Indeed, titanic oxide would form an 
excellent medium for the study of molecular absorption in the manner indicated by van Bemmelen (J.pr. Chem. [2], 26, 227).

On the assumption, therefore, that these values have equal weights, the final value from the whole 31 experiments becomes-

$$
\mathrm{Ti}=48 \cdot 013 \text {. }
$$

\begin{tabular}{|c|c|c|c|}
\hline \multirow{2}{*}{ Series } & \multicolumn{3}{|r|}{ Diff. from mean. } \\
\hline & $I \ldots \ldots \ldots \ldots$ & $48 \cdot 014$ & $+\quad 0.001$ \\
\hline & II $\ldots \ldots \ldots \ldots$ & $48 \cdot 016$ & 0.003 \\
\hline & III $\ldots \ldots \ldots \ldots$ & $47 \cdot 969$ & 0.044 \\
\hline & IV ... & $48 \cdot 031$ & 0.018 \\
\hline & $\nabla \ldots \ldots \ldots \ldots$ & $48 \cdot 057$ & 0.044 \\
\hline & VI.......... & $47 \cdot 989$ & 0.024 \\
\hline & Mean ..... & $48 \cdot 013$ & \\
\hline
\end{tabular}

Probable error of one series $= \pm 0.021$

Probable error of result .. $= \pm 0.0085$

This number, 48.01 , differs but slightly from that obtained by Rose in the experiments on which he set the greatest weight; it varies, however, by more than two units from the final number adopted by Pierre, viz., $50 \cdot 25$, and which has hitherto been commonly accepted as the most trustworthy value for Ti.

It will be observed, too, that the number 48.01 is in accordance with the value required by the Periodic Law. Mendelejeff's prevision thus receives a complete experimental confirmation.

It will also not escape notice that 48.01 is practically a whole number. It might be urged that the remarks made by Mallet at the close of his admirable memoir on the atomic weight of aluminium (Phil. Trans., 171, 1033) are hardly less applicable to the case of titanium. We must, I think, concede, with Mallet, that facts impartially looked at require us to admit that Prout's hypothesis is not as yet absolutely overthrown. Even if we discard altogether Dumas' asssumption, and have regard only to the indications of Prout's law, in the form originally enunciated by him, the fact that so large a pro. portion of the very best determined values approximate to integers is too significant to be lightly set aside. Nevertheless, I do not wish to attach an undue importance to the instance of titanium. Anyone who has worked at all with the haloild compounds of this element would, I think, refrain from basing a conclusion of so momentous a character on the unsupported evidence which such bodies might afford. I should suppose that these substances would be among the very last compounds which any chemist who set himself to test the validity of Prout's law would select as affording a suitable experimental basis. 
I desire, in conclusion, to express my acknowledgments to the Society for their very liberal grant from the Research Fund towards the expenses of this investigation. My thanks also are due to my assistant, Mr. Herbert Ingle, for his ready and intelligent aid in what has proved to be a somewhat tedious and protracted piece of work. 